\title{
Learner Autonomy in East Asian University Contexts
}

\author{
Jonathan Aliponga \\ Christopher Johnston \\ Yasuko Koshiyama \\ Tina Ries \\ Thomas Rush \\ Kansai University of International Studies, Hyogo, Japan \\ E-mail: alipongaj@kuins.ac.jp
}

\section{Doi:10.5901/jesr.2013.v3n7p83}

\begin{abstract}
There is no doubt that learner autonomy plays a very important role in successful language acquisition. However, there has been an extensive discussion of whether or not learner autonomy is an exclusively Western cultural construct. Some researchers argue that the concept of learner autonomy is perceived differently in different cultures, and the influence of sociocultural contexts cannot be ignored when trying to implement learner autonomy. Considering the importance of learner autonomy in language acquisition and how it varies according to the socio-cultural context, this paper looked into EFL students' perceptions of learner autonomy in East Asian university English classes taught by native speakers of English (NSE) and nonnative speakers of English (NNSE), and the perceptions of native speakers of English (NSE) and non-native speakers of English (NNSE) in terms of the implementation of learner autonomy in their English language classes.
\end{abstract}

Keywords: learner autonomy; autonomy; language learning; EFL; language teaching

\section{Introduction}

The importance of autonomy in second language acquisition and how autonomy varies according to cultural contexts have been studied widely in recent years. Researchers have looked at the role of autonomy in language learning and some have concluded that learner autonomy is a very important variable in successful acquisition. Literature suggests that autonomous learners explicitly accept responsibility for their learning, share in the setting of learning goals, take initiatives in planning and executing learning activities, and regularly review their language learning and evaluate its effectiveness (Holec, 1981; Little, 1991). Furthermore, autonomous language learners work well with teachers and peers and develop a sense of interdependence by sharing their learning goals (Ustunluoglu, 2009; Benson, 2001). Littlewood (1999) refers to the former autonomy as proactive, while the latter as reactive.

Proactive autonomy is associated with the autonomy discussed in the West, in which learners are able to establish a personal agenda for learning (Little, 1994), which affirms their individuality and sets up directions in a world which they themselves have partially created. In reactive autonomy, on the other hand, learners do not create their own directions, but once a direction has been initiated, they will be able to organize their resources autonomously in order to reach their goal. Learners who have this kind autonomy can learn vocabulary without being pushed, can do examination papers on their own initiative, or can organize themselves into groups in order to cover the reading for an assignment.

Little (1991) presents three arguments for developing learners capable of autonomous behavior is necessary in language instruction. The first argument is that autonomous learners are capable of reflective thinking. The second argument is that autonomous learners are intrinsically motivated and proactively committed to their learning. The third argument is that autonomous learners possess the highly developed social skills necessary for using their language skills in social contexts.

There has also been an extensive discussion of whether or not learner autonomy is an exclusively Western cultural construct. Some researchers argue that the concept of learner autonomy is perceived differently in different cultures and the influence of socio-cultural contexts cannot be ignored when trying to implement learner autonomy 
(Littlewood, 1999; Benson, 2001; Holliday, 2003).

Cao (2011) describes the differences between preferred learning styles and approaches in Western cultures and Asian cultures. Cao concludes that Confucian ideology and autonomous learning may not be compatible because while Western cultures tend to value independence, creativity, and critical thinking, Eastern cultures do not. Yildirim (2012) found that Indian students learning English as a second language in the U.S. were not ready to exercise autonomy and take responsibility for making decisions in learning and teaching methods as is expected in the American educational setting. Aoki and Smith (1999) found similarly that learning behavior may be culturally conditioned. Despite this, Holliday (2003) found evidence that learner autonomy is a psychological phenomenon that transcends culture as learners from different cultures are autonomous in their own ways.

Should the preceding arguments of cultural differences in the perception of learner autonomy be true, it follows that students behavior may differ according to the context. One possibility is that learners may exercise more learner autonomy in the classes taught by native speakers of English, who may be pedagogically more accustomed to learner autonomy in their own cultures, than in the classes taught by non-native speakers of English. This is because, as Borg (1998) argues, teachers' pedagogical beliefs in language instruction influence students' behaviors. Research is needed to investigate this possibility further as the information could prove useful for designing effective teacher training programs for native and non-native English teachers with different training needs (Littlewood, 1999).

Based on the above argument about the importance of autonomy and how it varies according to the socio-cultural context provided above, this paper sought to investigate two main questions:

1. What are students' perceptions of learner autonomy in university English classes taught by native speakers of English (NSE) and non-native speakers of English (NNSE)?

2. What are the perceptions of native speakers of English (NSE) and non-native speakers of English (NNSE) in terms of the implementation of learner autonomy in their English language classes?

\section{Research methodology}

\subsection{Participants}

Two groups of participants from a private university in Japan were involved in this study. The first group involved teachers, three native speakers of English (NSE) and four non-native speakers of English (NNSE). Native speakers of English (NSE) in this study is defined as teachers with English as their first language such as those born in the U.S., Canada, Australia, and the U.K., while non-native speakers of English (NNSE) refers to Japanese teachers of English.

The second group of participants consisted of 40 university students who are taking English Education as their field of specialization, plus 291 university students majoring in social welfare, and taking a basic English course at the time the survey was conducted. The 40 participants are first and second year students taught by NSE. The 291 participants are also first and second year students taught by NNSE.

\subsection{Instrument}

Littlewood's (1999) 10-item questionnaire, which was based on his ten predictions, was adapted and modified for this study. Prediction 1: East Asian students will have a strong inclination to form in-groups, which work towards common goals. Prediction 2: East Asian students will be eager to engage in activities that involve discussions within groups. Prediction 3: East Asian students will be concerned to maintain harmony within their groups. Prediction 4: In an open classroom, East Asian students will be reluctant to 'stand out' by expressing their views or raising questions, particularly if this might be perceived as expressing public disagreement. Prediction 5: East Asian students will perceive the teacher as an authority figure whose superior knowledge and control over classroom learning events should not be questioned. Prediction 6: East Asian students will see knowledge as something to be transmitted by the teacher rather than discovered by the learners. Prediction 7: East Asian students will expect the teacher, as the holder of authority and knowledge, to be responsible for the assessment of learning. Prediction 8: East Asian students will show strong motivation to follow through learning tasks that have been set, provided they perceive the practical value of these tasks. Prediction 9: East Asian students' motivation will be strengthened when success contributes to the goals or prestige of significant in-groups. Prediction 10: A high level of achievement motivation combined with a strong awareness of group expectations might lead East Asian students to be very concerned to perform well and correctly in what they do in class.

The questionnaire for students consists of two parts. Part 1 contains basic information such as gender, year level, 
university type, gender of teacher whose class is being evaluated, the course being evaluated, and the native language of the teacher being evaluated. Part 2 has 10 items adopted from Littlewood's questionnaire.

The questionnaire for teachers also has two parts. Part 1 also contains basic information such as gender, university type, native language, course they are evaluating at the time of the survey, and number of years of teaching English. Part 2 also has 10 items adapted from Littlewood's questionnaire. His questionnaire was intended for university students; therefore, the questions were rephrased for the teachers. For example, Question 1 "I like activities where I am part of a group which is working toward common goals" was modified to "I like to use activities where learners are part of a group which is working toward common goals."

In Part 2 for both questionnaires, Questions 1, 2 and 3 reflect the importance of relationships within groups. Question 4 is about student's attitude towards 'standing out' in the classroom situation. Questions 5, 6 and 7 focus on teacher authority and the transmission of knowledge. Questions 8, 9 and 10 relate to socially oriented motivation.

Responses in Part 2 were scored from 4 (Strongly Agree) to 1 (Strongly Disagree) on a Likert scale with no neutral, middle position. A score of 4 indicates a strong agreement while a score of 1 shows a strong disagreement. The neutral choice was eliminated because the research was about classroom autonomy, and all participants were familiar with the research variables being measured. Also, as has commonly been observed, students often select the neutral choice, which makes the interpretation of results more difficult. For ease of interpretation, the data were collapsed into a two-point scale. For example, data for "Strongly Agree" and "Agree" were merged and labeled as "Agree," while data for "Strongly Disagree" and "Disagree" were merged and labeled as "Disagree."

The questionnaire was translated into Japanese and was checked for clarity and accuracy by a Japanese professor of English. To ensure the comprehensibility of the questionnaire, it was piloted with a test group of university students and was revised and finalized using their feedback.

\section{Results}

Table 1. Student Perceptions of Learner Autonomy in the Classrooms Taught by Native Speakers of English (NSE) and Non-native Speakers of English (NNSE)

\begin{tabular}{|c|c|c|c|c|c|c|}
\hline & \multicolumn{3}{|c|}{ NSE $(n=40)$} & \multicolumn{3}{|c|}{ NNSE $(n=291)$} \\
\hline & A (\%) & $\mathrm{D}(\%)$ & $\mathrm{M}$ & A (\%) & $\mathrm{D}(\%)$ & $\mathrm{M}$ \\
\hline $\begin{array}{l}\text { Q1. I like activities where I am part of a group which is working toward } \\
\text { common goals }\end{array}$ & 95 & 5 & $\begin{array}{c}3.1 \\
A\end{array}$ & 86 & 14 & $\begin{array}{c}3.0 \\
A\end{array}$ \\
\hline $\begin{array}{l}\text { Q2. I like to take part in activities which involve discussions within a } \\
\text { group }\end{array}$ & 90 & 10 & $\begin{array}{c}3.0 \\
\mathrm{~A}\end{array}$ & 74 & 26 & $\begin{array}{c}2.8 \\
A\end{array}$ \\
\hline $\begin{array}{l}\text { Q3. When I am working in a group, I like to help maintain a sense of } \\
\text { harmony in the group }\end{array}$ & 98 & 3 & $\begin{array}{c}3.25 \\
A\end{array}$ & 90 & 10 & $\begin{array}{c}3.17 \\
A\end{array}$ \\
\hline $\begin{array}{l}\text { Q4. In the open classroom, I often feel hesitant to 'stand out' by } \\
\text { voicing my opinions and questions }\end{array}$ & 43 & 58 & $\begin{array}{c}2.35 \\
D\end{array}$ & 59 & 41 & $\begin{array}{c}2.66 \\
A\end{array}$ \\
\hline Q5. In the classroom, I see the teacher as an authority figure & 75 & 25 & $\begin{array}{c}2.88 \\
A\end{array}$ & 68 & 32 & $\begin{array}{c}2.78 \\
A\end{array}$ \\
\hline $\begin{array}{l}\text { Q6. I tend to see knowledge as something to be 'transmitted by the } \\
\text { teacher rather than 'discovered' by me as a learner }\end{array}$ & 23 & 78 & $\begin{array}{c}2.13 \\
D\end{array}$ & 41 & 60 & $\begin{array}{c}2.34 \\
D\end{array}$ \\
\hline $\begin{array}{l}\text { Q7. I expect the teacher (rather than me, myself) to be responsible for } \\
\text { evaluating how much I have learned }\end{array}$ & 25 & 75 & $\begin{array}{c}2.13 \\
D\end{array}$ & 29 & 71 & $\begin{array}{c}2.17 \\
D\end{array}$ \\
\hline $\begin{array}{l}\text { Q8. I feel strong motivation to follow through learning tasks of which I } \\
\text { perceive the practical value }\end{array}$ & 95 & 5 & $\begin{array}{c}3.28 \\
A\end{array}$ & 78 & 23 & $\begin{array}{c}2.96 \\
A\end{array}$ \\
\hline $\begin{array}{l}\text { Q9. I feel more motivated to work when my own success contributes to } \\
\text { the goals or prestige of significant groups (e.g. family, other students). }\end{array}$ & 90 & 10 & $\begin{array}{c}3.23 \\
A\end{array}$ & 85 & 15 & $\begin{array}{c}3.12 \\
A\end{array}$ \\
\hline $\begin{array}{l}\text { Q10. In the classroom I feel very concerned to perform well and } \\
\text { correctly in what I do. }\end{array}$ & 88 & 13 & $\begin{array}{c}2.98 \\
A\end{array}$ & 70 & 30 & $\begin{array}{c}2.83 \\
A\end{array}$ \\
\hline
\end{tabular}

n- Total number of respondents, A - Agree, D - Disagree, NSE - Native speaker of English, NNSE - Non-native speaker of English, M - mean agreement (1=Strongly Disagree, 4 = Strongly Agree)

As shown in Table 1, the students had the same perceptions of learner autonomy in the classrooms taught by native speakers of English (NSE) and non-native speakers of English (NNSE) as far as Q1, Q2, Q3, Q5, Q6, Q7, Q8, Q9 and Q10 were concerned. Specifically, most of the students liked to be part of a group that worked toward a common goal (NSE: $A=95 \%, M=3.1$; NNSE: $A=89 \%, M=3.0$ ), be involved in group discussions (NSE: $A=90 \%, M=3.0 ;$;NSE: $A=74 \%$, 
$M=2.8$ ), and to maintain a sense of harmony in a group ((NSE: $A=98 \%, M=3.25$; NNSE: $A=90 \%, M=3.17$ ). Most of the students also considered teachers to be an authority figure (NSE: $A=75 \%, M=2.88$; NNSE: $A=68 \%, M=2.78$ ), were highly motivated to accomplish learning tasks of practical value (NSE: $A=95 \%, M=3.28$; NNSE: $A=78 \%, M=2.96$ ), were more motivated to accomplish the learning tasks that contributed to the goals or prestige of their groups (NSE: $A=90 \%$, $M=3.23$; NNSE: $A=85 \%, M=3.12$ ), and felt very concerned to perform well and correctly in what they did (NSE: $A=88 \%$, $M=2.98$; NNSE: $A=70 \%, M=2.83$ ).

On the other hand, there are two points where most of the student participants from the two groups of teachers disagreed. They did not agree that knowledge should be transmitted by the teacher rather than discovered by them (NSE: $\mathrm{D}=78 \%, \mathrm{M}=2.13$; NNSE: $\mathrm{A}=60 \%, \mathrm{M}=2.34$ ), and they did not expect teacher to be responsible for evaluating their learning (NSE: $A=75 \%, M=2.13$; NNSE: $A=71 \%, M=2.17$ ).

Finally, the students from the two groups of teachers differed in their perceptions on one point. More than half of the students in the class of NSE were not hesitant to 'stand out' to voice their opinions and questions ( $D=58 \%, M=2.35)$, while the same number of students taught by NNSE felt otherwise (NNSE: $A=59 \%, M=2.66$ ).

Table 2. Teacher perceptions of learner autonomy in their classrooms

\begin{tabular}{|c|c|c|c|c|c|c|}
\hline & \multicolumn{3}{|c|}{$\operatorname{NSE}(n=3)$} & \multicolumn{3}{|c|}{ NNSE $(n=4)$} \\
\hline & $\mathrm{A}(\%)$ & $\mathrm{D}(\%)$ & $\mathrm{M}$ & $\mathrm{A}(\%)$ & $\mathrm{D}(\%)$ & M \\
\hline $\begin{array}{l}\text { Q1. I like to use activities where learners are part of a group } \\
\text { which is working toward common goals }\end{array}$ & 67 & 33 & $\begin{array}{c}3.0 \\
A\end{array}$ & 80 & 20 & $\begin{array}{c}3.40 \\
\mathrm{~A}\end{array}$ \\
\hline $\begin{array}{l}\text { Q2. I like to have activities in my class which involve learner } \\
\text { discussions within a group }\end{array}$ & 67 & 33 & $\begin{array}{c}2.67 \\
A\end{array}$ & 60 & 40 & $\begin{array}{c}3.0 \\
A\end{array}$ \\
\hline $\begin{array}{l}\text { Q3. When learners are working in a group, I like to see them } \\
\text { helping to maintain a sense of harmony in the group }\end{array}$ & 66 & 33 & $\begin{array}{c}2.67 \\
A\end{array}$ & 80 & 20 & $\begin{array}{c}3.20 \\
A\end{array}$ \\
\hline $\begin{array}{l}\text { Q4. In the open classroom, I often feel uncomfortable when } \\
\text { learners 'stand out' by voicing their opinions and questions }\end{array}$ & 0 & 100 & $\begin{array}{c}1.33 \\
D\end{array}$ & 0 & 100 & $\begin{array}{l}1.40 \\
D\end{array}$ \\
\hline Q5. In the classroom, I see myself as an authority figure & 0 & 100 & $\begin{array}{c}1.33 \\
D\end{array}$ & 60 & 40 & $\begin{array}{c}2.40 \\
D\end{array}$ \\
\hline $\begin{array}{l}\text { Q6. I tend to see knowledge as something to be 'transmitted' } \\
\text { by me, the teacher, rather than 'discovered' by the learner }\end{array}$ & 0 & 100 & $\begin{array}{c}1.33 \\
D\end{array}$ & 20 & 80 & $\begin{array}{c}1.80 \\
D\end{array}$ \\
\hline $\begin{array}{l}\text { Q7. As a teacher, I should be responsible, rather than the } \\
\text { students, for evaluating how much students have learned }\end{array}$ & 33 & 66 & $\begin{array}{l}2.0 \\
D\end{array}$ & 80 & 20 & $\begin{array}{c}2.80 \\
A\end{array}$ \\
\hline $\begin{array}{l}\text { Q8. I like to see students feeling a strong motivation to follow } \\
\text { through learning tasks of which they perceive the practical value }\end{array}$ & 67 & 33 & $\begin{array}{c}3.0 \\
A\end{array}$ & 100 & 0 & $\begin{array}{c}3.20 \\
A\end{array}$ \\
\hline $\begin{array}{l}\text { Q9. I believe students feel more motivated to work when their } \\
\text { own success contributes to the goals or prestige of significant } \\
\text { groups (e.g. family, other students) }\end{array}$ & 67 & 33 & $\begin{array}{c}3.0 \\
A\end{array}$ & 100 & 0 & $\begin{array}{c}3.20 \\
A\end{array}$ \\
\hline $\begin{array}{l}\text { Q10. In the classroom I feel very concerned to see learners } \\
\text { perform well and correctly in what they do }\end{array}$ & 67 & 33 & $\begin{array}{c}2.33 \\
D\end{array}$ & 80 & 20 & $\begin{array}{c}3.20 \\
\mathrm{~A}\end{array}$ \\
\hline
\end{tabular}

Table 2 reveals that native speakers of English (NSE) and non-native speakers of English had the same perceptions of learner autonomy in their classrooms in regard to Q1, Q2, Q3, Q8 and Q9. Most of the teachers liked their students to be part of a group that worked toward a common goal (NSE: $A=67 \%, M=3.0$; NNSE: $A=80 \%, M=3.40$ ), to be involved in group discussions (NSE: $A=67 \%, M=2.67$; NNSE: $A=60 \%, M=3.0$ ), and to maintain a sense of harmony in a group (NSE: $A=66 \%, M=2.67$; NNSE: $A=80 \%, M=3.20$ ). Also, most of the teachers liked seeing their students have high motivation to accomplish learning tasks of practical value (NSE: $A=67 \%, M=3.0$; NNSE: $A=100 \%, M=3.20$ ), and be more motivated to accomplish the learning tasks that contributed to the goals or prestige of their groups (NSE: $A=67 \%, M=3.0$; NNSE: $A=100 \%, M=3.20$ ).

On the other hand, there are three points where all of the native speakers of English teachers and non-native speakers of English teachers disagreed. All teachers disagreed that they were hesitant to see their students 'stand out' to voice their opinions and questions (NSE: $D=100 \%, M=1.33$; NNSE: $D=100 \%, M=1.40$ ). They also did not agree that they were an authority figure (NSE: $D=100 \%, M=1.33$; NNSE: $D=60 \%, M=2.40$ ), and did not see knowledge to be transmitted only by them but discovered by students themselves (NSE: $D=100 \%, M=1.33$; NNSE: $D=80 \%, M=1.80$ ).

Finally, the two groups of teachers differed in their perceptions on two points. Most of the native speakers of 
English did not think that they should be responsible for evaluating how their students learned, but it should be the students' responsibility ( $D=66 \%, M=2.0)$, while a similar number of non-native speakers of English felt otherwise $(A=80 \%$, $M=2.80$ ). Also, while the native speakers of English teachers were not very concerned to see their students perform well and correctly in what they did $(D=67 \%, M=2.33)$, the non-native speakers of English teachers felt otherwise $(A=80 \%$, $M=3.20)$.

\section{Discussion}

In Table 1, the results show that students had similar perceptions of autonomy regardless of whether NSE or NNSE taught the class, in all but one question. Specifically, the students taught by NSE and NNSE agreed with questions that reflect the importance of relationships within the group (Q1, Q2 and Q3; the average score of NSE $=3.12$ and NNSE = 2.99). These results are similar to the findings found by Littlewood (1999) who utilized 50 Hong Kong university students learning English. One main reason why Japanese students feel more autonomous and open to learn and discuss utilizing group work as opposed to individual work is that Japanese value collectivism over individualism and collaboration over competition (Samovar \& Porter, 1995). This claim is supported by the study of Nozoe (1993) in which a Japanese student wrote that most Japanese have a strong need to belong to a group. Moreover, in a large-scale study of students' attitudes and proficiency in Hong Kong, Littlewood and Liu (1996) and Chan (1995) found that group discussion was students' preferred activity in senior English classes at school and that they were equally keen to do most of the talking in English classes at university.

Like the findings of Littlewood (1999), the students taught by NSE and NNSE also agreed on questions that indicate socially oriented motivation (Q8, Q9 and Q10; the average score of NSE = 3.16 and NNSE = 2.97). Many studies indicate that East Asian students' achievement motivation is often socially rather than individually oriented (Markus \& Kitayama, 1992, 1991b; Ho, 1986; Salili, 1996). The results of these studies show that the expectations of students' families are one of the strongest reasons that students often report for striving to enter university. The studies of Chan (1995) and Littlewood and Liu (1996) also reveal that students are eager not only to gain greater fluency in English but also to have their mistakes corrected by the teachers. This explains why a high level of achievement motivation combined with a strong awareness of group expectations leads East Asian students to be very concerned to perform well and correctly in what they do in class (Littlewood, 1999).

As far as clear status difference between students and teachers in the classroom is concerned, the average score (NSE = 2.38 and NNSE = 2.43) of Q5, Q6 and Q7 indicates the disagreement of students taught by NSE and NNSE. Specifically, the students taught by NSE and NNSE considered their teacher as an authority figure in the classroom, but they disagreed that knowledge should be transmitted by the teacher rather than discovered by the students themselves, and that the teacher should be the holder of authority and knowledge and responsible for the assessment of learning. These results contradict the perceptions that East Asian students will consider the teacher as an authority figure whose superior knowledge and control over classroom learning events should not be questioned (Dzau, 1990; Jones, 1995). Littlewood, who interviewed an experienced teacher, reports that amongst themselves students frequently questioned their teacher's judgement. This suggests that students' overt acceptance of the teacher's authority may be due more to the constraints of the situation than to the internalized recognition of authority that is often taken to be. This means that students will find it normal to engage in modes of learning which are teacher-centered and in which they receive knowledge rather than interpret it. This is supported by the survey of Littlewood and Liu (1996) in which Hong Kong students named listening to the teacher as their most frequent activity in senior school English classes. Another support to this finding is revealed in the study of Gamble et al (2011) who found that Japanese university students at various levels of motivation perceived themselves as being capable of being more involved in their own learning. However, they often did not act on these feelings due to a perception that it was the teacher's responsibility or due to a lack of confidence. They further suggest that there is ample room in the typical Japanese university classroom for opportunities to change direction for students taking more responsibilities for their own learning. This should include educating and training students in learning strategies to narrow the gap between their perceived abilities and the learning responsibilities they take on.

The one difference in student perceptions of autonomy in regard to classes taught by NSE and NNSE was where students were asked if they felt hesitant to 'stand out' by voicing their opinions and questions. The results show that students felt less hesitant to speak out in classes taught by NSE. Why would students feel more at ease to speak out and voice opinions in classes taught by native speakers of English? According to Littlewood (1999), in an open classroom, East Asian students will be reluctant to 'stand out' by expressing their views or raising questions, particularly if this might 
be perceived as expressing public disagreement. This is the experience commented on by many teachers, both with a Western background (Anderson 1993) and with an East Asian background (Song 1995; Tsui 1996). Students perceive the teacher as an authoritative figure and may feel that expressing personal views in class may disrupt the teacherstudent harmony. The results in Table 1 show that Japanese students may have perceived NSE to be less of an authoritative symbol compared to NNSE; therefore, felt less inhibited to voice their views in front of their peers.

Regarding teacher perceptions of learner autonomy in their classrooms, NSE and NNSE agreed on all but two questions. Specifically, NSE and NNSE agreed with questions that reflect the importance of relationships within the group (Q1, Q2 and Q3; average score of NSE = 2.78 and NNSE = 3.2). Teacher perceptions conform with student perceptions. These results suggest that NSE saw the importance attached to the interdependent self in East Asian culture, that is why students forming in-groups to work towards common goals was practiced in their classrooms.

As far as the socially-oriented motivation of students is concerned, NSE and NNSE expressed agreement that it is important in their learning as shown in the average score of Q8, Q9 and Q10; NSE = 2.78 and NNSE = 3.2). However, NSE were not very concerned to see their students perform well and correctly in what they did. These findings suggest that while native speakers of English recognized that their students would show strong motivation to follow through learning tasks perceived as having practical value, which could be strengthened when success could contribute to the goals or prestige of significant in-groups, they did not think correctness in performance could be a contributing factor in the classroom success and could inhibit students to participate in class due to fear of making mistakes or fear of ridicule (Tsui, 1996).

Like the response of their students, NSE and NNSE expressed disagreement with regard to teacher authority and transmission of knowledge as shown by the average score of Q5, Q6 and Q7; NSE = 1.33 and NNSE = 1.40). Specifically, NSE believed that assessment of learning should not only be their responsibility, but also the students'. NNSE thought otherwise.

Another interesting finding was both NSE and NNSE had similar autonomous perceptions when it comes to not feeling authoritative and allowing students to discover knowledge and voice their opinions and questions. Both NSE and NNSE believed that learners would be more motivated in groups and should work in groups to help each other to achieve a common goal. These findings suggest that teachers of all societies viewed autonomous learning in pairs and groups as a positive aspect of education.

\section{Conclusion}

Based on the results, the following can be concluded. First, NSE and their students as well as NNSE and their students agreed to the importance of students working together in groups to achieve their common goal. These results especially imply that NSE understood that it was important for students to have harmony and cooperation in the in-group to achieve their goal, which NSE themselves implemented in their classrooms. This, in turn, might have influenced students' perceptions. It was expected that the students of NSE would claim the right to express themselves, make personal choices and strive for self-actualization, but the results revealed otherwise. Students preferred to cooperate to achieve harmony in the in-group.

Second, the perceptions of the students are consistent with the perceptions of their teachers, that is, students and their teachers favored socially oriented motivation. However, NSE were not very concerned to see their students perform well and correctly in what they did, which suggests that while native speakers of English recognized that their students would show strong motivation to follow through learning tasks perceived as having practical value, which could be strengthened when the success could contribute to the goals or prestige of significant in-groups, they did not think correctness in performance could be a contributing factor in the classroom success. It could, in fact, inhibit students to participate in class due to fear of making mistakes or fear of ridicule (Tsui, 1996).

Third, students taught by NSE and NNSE considered their teacher to be an authority figure in the classroom, but they did not think that knowledge should be transmitted by the teacher rather it should be discovered by the students themselves, and the teacher should be the holder of authority and knowledge and responsible for the assessment of learning. NSE and NNSE thought the same. However, NSE believed that assessment of learning should not only be their responsibility, but also the students'. NNSE thought otherwise.

Fourth, students felt less hesitant to speak out in classes taught by NSE. Japanese students may have perceived NSE to be less of an authoritative symbol compared to NNSE, therefore, felt less inhibited to voice their views in front of their peers. NNSE had similar autonomous perceptions when it comes to not feeling authoritative and allowing students to discover knowledge and voice their opinions and questions. However, these perceptions conflict with the perceptions 
of their students, suggesting that although NNSE were comfortable with students' expressing their own opinions in class, the learning environment may not provide opportunities for students to voice their opinions and questions.

Finally, the kind of autonomy that prevailed in the classrooms of NSE and NNSE is evidently reactive, which characterizes East Asian autonomy. Except for exercising their power and authority as teacher by controlling students' learning, giving responsibility to students to evaluate their own learning, and not focusing on correctness in students' classroom task performance, NSE believed in collectivism and value of effort and self-discipline. NNSE also believed in collectivism and value of effort and self-discipline. They disagreed on exercising their power and authority as teacher by controlling students' learning, but believed that they should play a major role in evaluating students' learning. These pedagogical beliefs seemed to influence students' behaviors.

Since there were only three NSE and four NNSE and an unequal number of student participants (students in NSE classrooms $=40$, students in NNSE classrooms $=291$ ), there is a danger of making a generalization about autonomy in the classrooms of NSE and NNSE. In order to make a good comparison between groups of students and teachers, data should be collected from at least 30 NSE and 30 NNSE, and balance in the number of student participants should be observed. It is also recommended that statistical method should be utilized to determine the significant difference in perceptions between groups of respondents.

\section{References}

Anderson, J. (1993). Is a communicative approach practical for teaching English in China? Pros and cons. System, 21, 471-480.

Aoki, N., \& Smith, R. (1999). Learner autonomy in cultural contexts: the case of Japan in D. Crabbe and S. Cotter (Eds), Learner autonomy in language learning: Defining the field and effecting change. Frankfurt: Lang, 19-27.

Benson, P. (2001). Teaching and researching autonomy in language learning. London: Longman.

Borg, S. (1998). Teachers' pedagogical systems and grammar teaching: A qualitative study. TESOL Quarterly, 32(1), 9-38.

Cao, T. N. (2011). Impacts of socio-culture on the development of autonomous learning: A lens of Vietnamese context. Journal of Studies in Education,1(1), 1-19.

Chan, V. N. K. (1995). Communicative language teaching: focus on the learner. Unpublished M.A. thesis, Hong Kong Polytechnic University.

Dzau, Y. (1990). English in China. Hong Kong: API Press.

Gamble, C., Aliponga, J., Koshiyama, Y., Wilkins, M., Yoshida, K. \& Ando, S. (2011). Examining Learner Autonomy Dimensions: Students' Perceptions of Their Responsibility and Ability. In A. Stewart \& N. Sonda (Eds.), JALT2011 Conference Proceedings. Tokyo: JALT.

Ho, D. Y. F. (1986). Chinese pattern of socialization: A critical review. In M. H. Bond (Ed.), The psychology of the Chinese people (pp. 1 - 37). New York: Oxford University Press.

Holec, H. (1981). Autonomy and foreign language learning. Oxford: Pergamon.

Holliday, A. (2003). Social autonomy: Addressing the dangers of culturism in TESOL. In D. Palfreyman and Smith, R.C. (Eds.). Learner autonomy across cultures: Language education perspectives. London: Palgrave Macmillan. 110-126.

Jones, J. F. (1995). Self-access \& culture: retreating from autonomy, ELT Journal. 49(3), 228-234.

Little, D. (1991). Learner autonomy 1: Definitions, issues and problems. Dublin: Authentik.

Little, D. (1994). Learner autonomy: A theoretical construct and its practical application. Die Neuren Sprachen, 93(5), 430-442.

Littlewod, W. (1999). Defining and developing autonomy in East Asian contexts. Applied Linguistics, 20(1), 71-94.

Littlewood, W. T., \& Liu, N. F. (1996). Hong Kong students and their English. Macmillan, Hong Kong.

Markus, H. R., \& Kitayama, S. (1991b). Cultural variation in the self concept. In J. Strauss and Goethals, G. R. (Eds.), The self: Interdisciplinary Approaches. New York: Springer. 18-47.

Markus, H. R., \& Kitayama, S. (1992). The what, why, and how of cultural psychology: A review of Shweder's thinking through cultures. Psychological Inquiry, 3, 357-364.

Salili, F. (1996). Accepting personal responsibility for learning. In D. A. Watkins and J. B. Biggs (Eds.), The Chinese learner: Cultural, psychological and contextual influences, 85-105. Hong Kong and Melbourne: CERC and ACER.

Samovar, L. A., \& Porter, R. E. (1995). Communication between cultures. Belmont, CA: Wadsworth Publishing Co.

Song, B. (1995). What does reading mean for East Asian students? College ESL, 5 (2), 35-48.

Tsui, A. (1996). Reticence and anxiety in second language learning. In Bailey, K., \& Nunan, D. (Eds.), Voices from the language classroom. Cambridge University Press, Cambridge, 145-167.

Ustunluoglu, E. (2009). Autonomy in language learning: Do students take responsibility for their learning? Journal of Theory and Practices in Education, 5 (2), 148-169.

Yildirim, O. (2012). A study on a group of Indian English as a second language learners' perceptions of autonomous learning. Turkish Online Journal of Qualitative Inquiry, 3(2), 18-29. 